DOI: 10.12731/2070-7568-2017-3-134-146

УДК 504.61:504.4

\title{
ОЦЕНКА ЭКОНОМИЧЕСКОГО УЩЕРБА В СЕЛЬСКОМ ХОЗЯЙСТВЕ СИБИРСКОГО ФЕДЕРАЛЬНОГО ОКРУГА ПОД ДЕЙСТВИЕМ ПРИРОДНЫХ И ТЕХНОГЕННЫХ ЧРЕЗВЫЧАЙНЫХ СИТУАЦИЙ
}

\section{Игнатьева А.В.}

В работе рассмотрены условия развития сельского хозяйства 8 регионах Сибирского федерального округа (СФО) за период c 1990 по 2013 гг. под действием чрезвычайных ситуаций (ЧС). Приведен ряд факторов, влияющих на развитие отраслей сельского хозяйства в различных регионах СФО. В ходе исследования на разработанной схеме наглядно отражен проиесс взаимодействия сельского хозяйства региона и общества. Отражень экономические потери отраслей сельского хозяйства региона от действия чрезвычайных ситуачий.

Цель - оценить потенциал устойчивого развития сельского хозяйства в регионах Сибирского федерального округа (СФО) и его изменение под действием природно-техногенных чрезвычайных cumуаиий.

Метод или методология проведения работы: в статье использовались экономико-математические методы, а также статистические методы анализа.

Результаты: получены наиболее информативные параметры, показывающие современное положение сельского хозяйства в регионах СФО и перспективы устойчивого развития.

Область применения результатов: полученные результать целесообразно применять экономическими субъектами, осуществляющими сельскохозяйственное производство в регионах СФО.

Ключевые слова: сельское хозяйство; производство; экономические потери; природно-техногенные чрезвычайные ситуации. 


\section{ASSESSMENT OF ECONOMIC DAMAGE IN AGRICULTURE OF THE SIBERIAN FEDERAL DISTRICT UNDER THE INFLUENCE OF NATURAL AND TECHNOGENIC EMERGENCY SITYATIONS}

\section{Ignateva A.V.}

The conditions for the development of agriculture in the regions of the Siberian Federal District (SFD) for the period from 1995 to 2013 are considered. Under the influence of emergency situations (ES). A number of factors affecting the development of agriculture in different regions of the Siberian Federal District are presented. In the course of the study, the developed scheme clearly reflects the process of interaction between the agriculture of the region and society. The economy losses of the agricultural branches of the region are reflected from the action of emergency situations.

Purpose - to assess the potential for sustainable development of agriculture in the regions of the SFD and its change under the influence of natural-technologized emergencies.

Methodology in article economic-mathematical methods, and also statistical methods of the analysis were used.

Results: the most informative parameters showing the current situation of agriculture in the regions of the SFD and possibilities for sustainable development.

Practical implications it is expedient to apply the received results the economic subjects which are carrying out agricultural production in the regions of the SFD.

Keywords: agriculture; production; economic losses; natural-technologized emergencies.

Оценка экономического ущерба в сельском хозяйстве от воздействия различных факторов - важное звено на пути движения страны в сторону устойчивого развития. Прогноз, оценка и меры по уменьшению потерь скота, посевов, молодняка - важное практическое направление в развитии сельского хозяйства. На урожайность сель- 
скохозяйственных культур, продуктивность сельскохозяйственных животных прямое или косвенное влияние оказывают самые различные факторы. Но самый главный фактор, определяющий специфику, масштабы и продуктивность ведения сельского хозяйства на какойлибо территории - физико-географические условия (рисунок 1).



Рис. 1. Схема факторов, влияющих на устойчивое развитие сельского хозяйства региона и влияния сельского хозяйства на территорию региона.

Примечание: $\longrightarrow$ влияние сельского хозяйства на различные факторы; влияние факторов на сельское хозяйство.

Рельеф территории, климатические условия, растительный и почвенный покров - синтез этих условий о какой-либо территории дает нам возможность определить потенциал территории для ведения сельского хозяйства. Но не менее важно определить специфику территории на случаи возникновения чрезвычайных ситуаций (ЧС). Этот показатель также важен, так как ЧС способны приносить огромные убытки в случае их возникновения.

По природно-климатическим условиям большая часть территории России расположена в зоне рискованного сельскохозяйствен- 
ного производства, вследствие чего АПК ежегодно несет огромные потери. Стихийные бедствия ежегодно охватывают территории от 50 до 70 субъектов Российской Федерации. Они являются источниками ЧС в сельском хозяйстве [11].

Последствия стихийных бедствий и чрезвычайных ситуаций для сельского хозяйства принято характеризовать категорией ущерба, который включает в себя потери и убытки. Полный экономический ущерб включает все виды материальных потерь и затрат, связанных с природными ЧС [8].

Согласно данным МЧС РФ, количество ЧС природного характера сильно варьируется в регионах СФО, как и количество ЧС техногенного характера (рисунок 2).

120

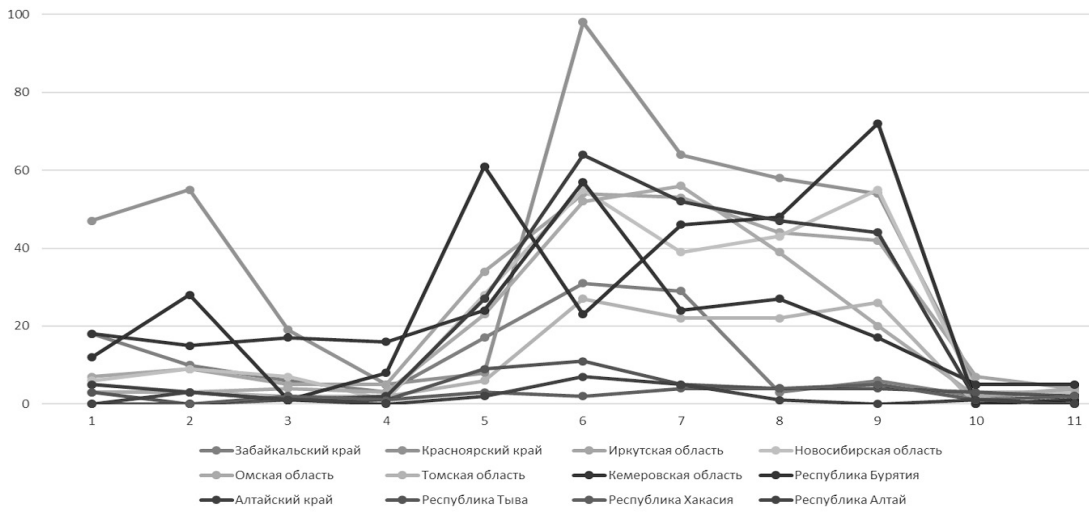

Pис. 2. Динамика ЧС природного характера в Сибирском федеральном округе

За рассматриваемый период с 2000 по 2010 гг. наибольшее количество ЧС природного характера было зафиксировано в Красноярском крае, Республике Бурятия, Иркутской области, Новосибирской области. Наименьшее количество ЧС природного характера было отмечено в Республиках Тыва, Хакасия и Алтай. Также важно отметить, что за рассматриваемый период во всех регионах СФО ЧС природного характера по количество достаточно сильно превышают количество ЧС техногенного характера. Это важно отметить, 
так как ЧС природного характера - наиболее вероятный источник для нанесения ущерба сельскому хозяйству в любом регионе.

Среди техногенных чрезвычайных ситуаций, которые наравне с природными чрезвычайными ситуациями могут повлечь за собой экономический ущерб в сельском хозяйстве нужно отметить: пожары, взрывы, обрушения зданий и т.д. Долю наносимого экономического ущерба сельскому хозяйству от чрезвычайных ситуаций техногенного характера сложно вычислить при отсутствии деления техногенных ЧС на виды. Но как предполагаемый возможный источник экономического ущерба в сельском хозяйстве их важно рассмотреть, так как их количество в каждом регионе СФО достаточно большое и не имеет тенденцию к снижению.

К поражающим факторам техногенных ЧС, которые могут повлечь за собой гибель сельскохозяйственных животных и посевов относятся:

- Ударная волна;

- Световое излучение;

- Химическое загрязнение окружающей среды и местности;

- Биологическое заражение местности;

- Сейсмические волны в случае техногенных землетрясений и т.д.

Распределение случаев чрезвычайных ситуаций в регионах Сибирского федерального округа выглядит по-разному (рисунок 3 ).

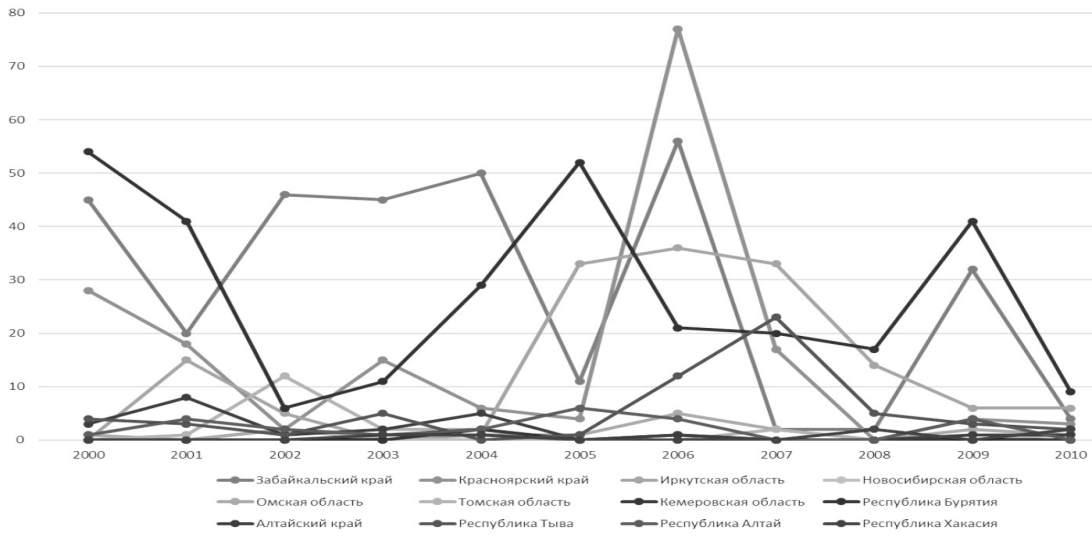

Pис. 3. Динамика ЧС техногенного характера в Сибирском федеральном округе 
Наибольшее количество ЧС техногенного характера за рассматриваемый период, по данным МЧС РФ, с 2000 по 2010 гг. приходится на Забайкальский край, Республику Бурятия, Красноярский край. Наименьшее количество ЧС техногенного характера за рассматриваемый период произошло в Республике Хакасия, Кемеровской и Новосибирской областях.

Последствия чрезвычайных ситуаций в животноводстве представляют собой прямые потери отрасли в результате воздействия чрезвычайных ситуаций, т.е. это будет погибшее поголовье всех

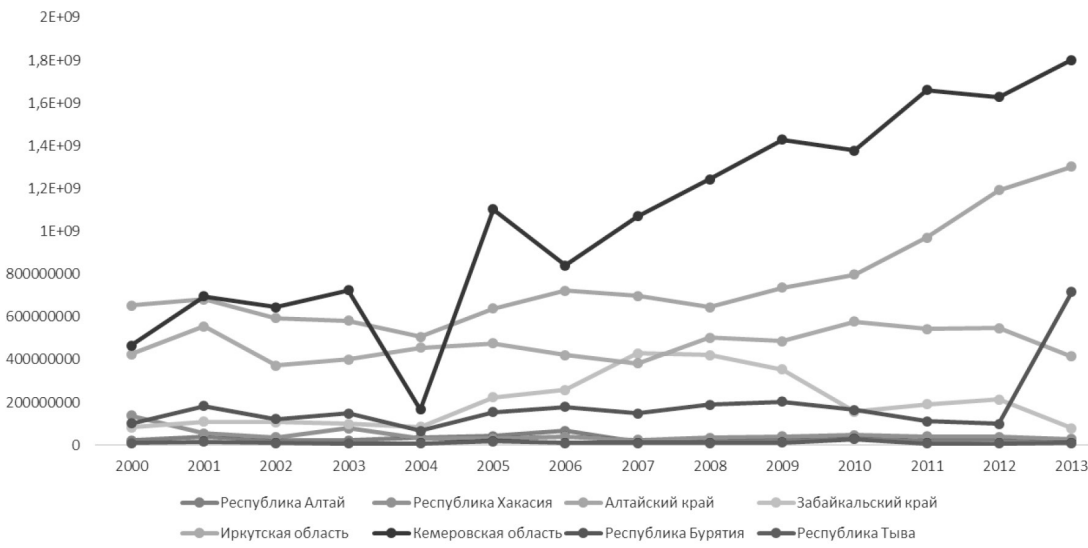

Рис. 4. Динамика экономического ущерба в отрасли животноводства от падежа крупного рогатого скота и свиней в регионах СФО

Ущерб в отрасли животноводства можно представить формулой:

$$
\text { Уж }=N o * Б c+N_{M O} * N c p * C,
$$

где $N o$ - численность погибших и вынужденно забитых животных основного стада, гол.;

Бс - балансовая стоимость 1 головы погибших и вынужденно забитых животных, руб.;

$N_{\text {мо }}$ - численность погибшего и вынужденно забитого поголовья молодняка и скота на откормке, гол.;

$N c p$ - средняя продуктивность молодняка и скота на откормке, кг/год;

$C$ - цена реализации основной продукции животноводства, руб./ц. 
Динамика экономического ущерба от падежа крупного рогатого скота в регионах представлена по-разному (рисунок 4).

Общая тенденция для экономического ущерба находится на самом высоком уровне среди регионов в Алтайском крае (среднее значение экономического ущерба за рассматриваемый период 503560260,2 руб.), причем величина ущерба год от года растет. Далее идет регионы, где также высок экономический ущерб от падежа крупного рогатого скота и отмечается тенденция к увеличению: Новосибирская область (среднее значение экономического ущерба за рассматриваемый период 436823018,4 руб.) и Томская область (среднее значение экономического ущерба за рассматриваемый период 386271428,6 руб.). В других регионах величина экономического ущерба отстает от перечисленных регионов: Красноярский край (среднее значение экономического ущерба за рассматриваемый период 345573962 руб.), Омская область (среднее значение экономического ущерба за рассматриваемый период 287328068,5 руб.). Далее идут регионы, сильно отстающие от перечисленных по величине экономического ущерба от падежа крупного рогатого скота: Иркутская область (среднее значение экономического ущерба за рассматриваемый период 131700813,2 руб.), Кемеровская область (среднее значение экономического ущерба за рассматриваемый период 89822774,74 руб.), Забайкальский край (среднее значение экономического ущерба за рассматриваемый период 55533160,93 руб.), Республика Бурятия (среднее значение экономического ущерба за рассматриваемый период 39271380,6 руб.), Республика Хакасия (среднее значение экономического ущерба за рассматриваемый период 34695547,59 руб.), Республики Алтай (среднее значение экономического ущерба за рассматриваемый период 27809060,29 руб.) и Тыва (среднее значение экономического ущерба за рассматриваемый период 10252567,26 руб.).

Далее перейдем к анализу отрасли растениеводства в регионах СФО.

Недобор урожая в расчетном году определяется разницей урожайности конкретной сельскохозяйственной культуры в расчетном году и уровня урожайности данной культуры, выбранного из ста- 
тистического ряда за последние пять лет. Отсюда оценка ущерба от стихийных бедствий и чрезвычайных ситуаций природного и техногенного характера в растениеводстве можно представить в следующем виде [5]:

$$
U=\sum S j * y j * C j,
$$

где $S j$ - фактическая площадь гибели посевов $j$-й сельскохозяйственной культуры или группы культур;

$y j$ - урожайность $j$-й сельскохозяйственной культуры или группы культур;

$C j$ - цена реализации единицы продукции $j$-й сельскохозяйственной культуры или группы культур.

Использовав данные Росстат [8], мы установили следующее. Распределение экономического ущерба от потери урожаев зерновых и зернобобовых в регионах различно. Наибольший экономический ущерб за рассматриваемый период характерен для Алтайского края, Омской области, Новосибирской области, Иркутской области. Среди других регионов различия не ярко выражены (рисунок 5).

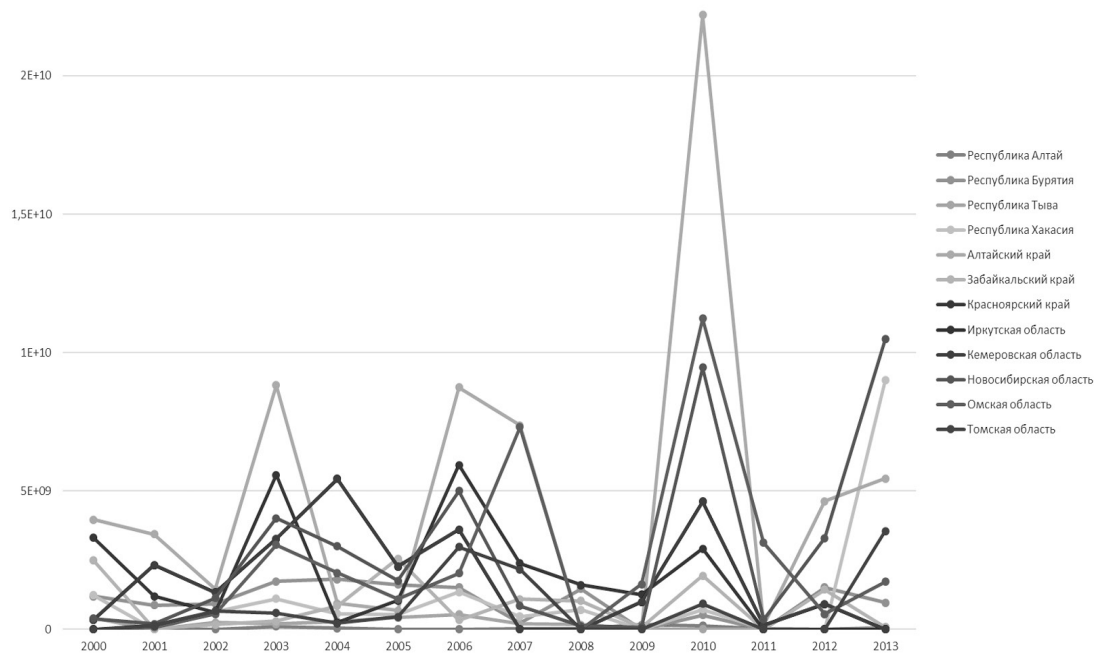

Рис. 5. Динамика экономического ущерба в отрасли растениеводства регионов Сибирского федерального округа 
Динамика экономического ущерба от гибели посевов картофеля среди регионов различна. Наибольший ущерб характерен для следующих регионов: Омская область, Иркутская область, Красноярский край, Кемеровская область. Среди остальных регионов различия в экономическом ущербе не столь ярко выражена.

Динамика экономического ущерба от потери урожаев льнадолгунца в регионах различна. Наибольший экономический ущерб характерен для следующих регионов: Новосибирская область, Алтайский край, Томская область, Новосибирская область.

Наибольший экономический ущерб от гибели посевов подсолнечника отмечаются в Алтайском крае (среднее значение экономического ущерба за рассматриваемый период 622424427,1 руб.). Немного меньше экономический ущерб отмечается в Омской области (среднее значение экономического ущерба за рассматриваемый период 487116430,7 руб.). Практически одинаковый экономический ущерб и небольшая динамика отмечаются в Республике Алтай (среднее значение экономического ущерба за рассматриваемый период 0 руб.), Республике Хакасия (среднее значение экономического ущерба за рассматриваемый период 1332142,857 руб.), Красноярском крае (среднее значение экономического ущерба за рассматриваемый период 2416614,286 руб.), Кемеровской области (среднее значение экономического ущерба за рассматриваемый период 4671428,571 руб.), Новосибирской области (среднее значение экономического ущерба за рассматриваемый период 70050481,43 руб.). Также следует отметить, что часто встречаются годы, когда в ряде регионов СФО не отмечается экономический ущерб от гибели посевов подсолнечника.

В результате проделанной работы были сформулированы следующие выводы:

1. Распределение посевных площадей по регионам Сибирского федерального округа выглядит следующим образом. Наибольшие посевные площади находятся в Алтайском крае. С 1995 года наблюдается снижение доли площади, но с 2000 года посевы остаются практически на одном уровне. 
Алтайский край сохраняет лидирующее место по доле посевных площадей среди регионов Сибирского федерального округа. За Алтайским краем по площади посевов следует Омская область. В этом регионе доля посевных площадей остается практически неизменной с 1995 года до 2013 года. Затем идут Новосибирская область, Красноярский край, Кемеровская область, Иркутская область. Самые наименьшие площади посевов среди регионов Сибирского федерального округа в Томской области, Забайкальском крае, Республике Хакасия, Республике Бурятия, Республике Алтай и Республике Тыва.

2. Для планирования сельскохозяйственного производства на территории исследуемых регионов важно учитывать не только физико-географические условия, но и влияние чрезвычайных ситуаций в регионе. Распределение случаев чрезвычайных ситуаций в регионах Сибирского федерального округа выглядит по-разному. Наибольшее количество ЧС техногенного характера за рассматриваемый период с 2000 по 2010 гг. приходится на Забайкальский край, Республику Бурятия, Красноярский край. Наименьшее количество ЧС техногенного характера за рассматриваемый период произошло в Республике Хакасия, Кемеровской и Новосибирской областях. Количество ЧС природного характера также сильно варьируется в регионах СФО, как и количество ЧС техногенного характера. За рассматриваемый период с 2000 по 2010 гг. наибольшее количество ЧС природного характера было зафиксировано в Красноярском крае, Республике Бурятия, Иркутской области, Новосибирской области.

3. Динамика совокупного экономического ущерба от потерь крупного рогатого скота и свиней выглядит следующим образом. Наибольший экономический ущерб от потерь животных отмечается в Кемеровской области. Затем идет Алтайский край. В этих регионах также отмечается тенденция к росту экономического ущерба. Далее по мере снижения экономического ущерба идут следующие регионы: Иркутская область, 
Забайкальский край, Республика Бурятия, Республика Тыва, Республика Хакасия, Республика Алтай. В этих регионах практически на одном уровне год от года отмечается величина экономического ущерба.

4. Динамика общего экономического ущерба от потерь урожаев всех анализируемых культур выглядит следующим образом. Наибольший экономический ущерб характерен для следующих регионов: Алтайский край, Омская область, Новосибирская область, Красноярский край, Новосибирская область, Кемеровская область.

\section{Список литературы}

1. Акимов В.А., Новиков В.Д., Радаев Н.Н. Природные и техногенные ЧС: опасности, угрозы, риски. М., 2001. С. 344.

2. Гаджиев И.М., Овчинников С.М. Почвы средней тайги Западной Сибири. Новосибирск : Наука. Сиб. отд-ние, 1977. 152 с.

3. Кнауб Р.В. Комплексная оценка ущерба природных и техногенных катастроф на примере Сибирского федерального округа [Электронный ресурс] // Устойчивое инновационное развитие : проектирование и управление. 2012. №4. URL: http:/www.rypravlenie. $\mathrm{ru} / \mathrm{p}=1323$ (дата обращения: 25. 02. 2015).

4. Метелев С.Е. Устойчивое развитие Омской области: вчера, сегодня, завтра // Региональные проблемы преобразования экономики, 2012. № 2. C. 113-127.

5. Плющиков В.Г., Фатиев М.М. Статистические методы оценки и прогнозирования экономического ущерба от природных ЧС. М.: Из-во РУДН, 2012. С. 5-15.

6. Рудой Е.В., Краснов Е.В., Афанасьев Е.В., Григорьев Н.В. Сельское хозяйство Сибири в условиях реализации доктрины продовольственной безопасности Российской Федерации // Вестник Алтайского государственного аграрного университета, 2011. № 12 (86). С. $120-124$.

7. Сибирский региональный центр МЧС России [Электронный ресурс] / МЧС России. 2016. URL: http://siberian.mchs.ru/Regionalnij_ centr/Region (дата обращения: 06.05.2016). 
8. Федеральная служба государственной статистики [Электронный peсурс] / Росстат, 1999-2016. URL: http://www.gks.ru/ (дата обращения: 06.05.2016).

9. Цугленок О.М. Развитие сельского хозяйства Красноярского края // Вестник Казанского государственного аграрного университета, 2009. T. 4. № 4 (14). С. 101-105.

10. Черемисин А.А. Территориальная организация сельского хозяйства в Республике Алтай // Современные проблемы науки и образования. 2009. №1. 15 с.

11. Edward Bryant. Natural hazards. Cambridge, Cambridge University Press, 2006. 12 p.

\section{References}

1. Akimov V.A., Novikov V.D., Radaev N.N. Prirodnye $i$ tekhnogennye ChS: opasnosti, ugrozy, riski [Natural and Technogenic ES: dangers, threats, risks]. Moscow, 2001. 344 p.

2. Gadzhiev I.M., Ovchinnikov S.M. Pochvy sredney taygi Zapadnoy Sibiri [Soils of the middle taiga of the Western Siberia]. Novosibirsk : Nauka, Siberian Branch, 1977. 152 p.

3. Knaub R.V. Kompleksnaya otsenka ushcherba prirodnykh i tekhnogennykh katastrof na primere Sibirskogo federal'nogo okruga [Comprehensive assessment of damage to natural technogenic disasters by the example of the Siberian Federal District]. Ustoychivoe innovatsionnoe razvitie : proektirovanie i upravlenie [Sustainable innovative development: design and management]. 2012. №4. http://www.rypravlenie. $\mathrm{ru} / \mathrm{p}=1323$

4. Metelev S.E. Ustoychivoe razvitie Omskoy oblasti: vchera, segodnya, zavtra [Sustainable development of the Omsk region: yesterday, today, tomorrow]. Regional'nye problemy preobrazovaniya ekonomiki [Regional problems of economic transformation], 2012. №2, pp. 113-127.

5. Plyushchikov V.G., Fatiev M.M. Statisticheskie metody otsenki i prognozirovaniya ekonomicheskogo ushcherba ot prirodnykh ChS [Statistical methods for assessing and predicting economic damage from natural emergencies]. Moscow: the publishing house of RUPF, 2012, pp. 5-15. 
6. Rudoy E.V., Krasnov E.V., Afanas'ev E.V., Grigor'ev N.V. Sel'skoe khozyaystvo Sibiri v usloviyakh realizatsii doktriny prodovol'stvennoy bezopasnosti Rossiyskoy Federatsii [Agriculture of Siberia in the context of the implementation of the doctrine of food security of the Russian Federation]. Bulletin of the Altay State Agrarian University. 2011. №12 (86), pp. 120-124.

7. Sibirskiy regional'nyy tsentr MChS Rossii [Siberian Regional Center of the Ministry of Emergencies of Russia]. The Ministry of Emergencies of Russia. 2016. http://siberian.mchs.ru/Regionalnij_centr/Region

8. Federal service of state statistics. Russtat, 1999-2016. http://www.gks.ru/

9. Tsuglenok O.M. Razvitie sel'skogo khozyaystva Krasnoyarskogo kraya [The development of agriculture in the Krasnoyarsk region]. Bulletin of the Kazan State Agrarian University. 2009. V. 4. №4 (14), pp. 101-105.

10. Cheremisin A.A. Territorial'naya organizatsiya sel'skogo khozyaystva $\mathrm{v}$ Respublike Altay [Territorial organization of agriculture in the Altay Republic]. Modern problems of science and education. 2009. №1. 15 p.

11. Edward Bryant. Natural hazards. Cambridge, Cambridge University Press, 2006. 12 p.

\section{ДАННЫЕ ОБ АВТОРЕ}

Игнатьева Анна Владимировна, аспирант кафедры природопользования

Национальный исследовательский Томский государственный университет

пр. Ленина, 36, г. Томск, Томская область, 634050, Российская Федерачия

anna_tomsktsu@mail.ru

\section{DATA ABOUT THE AUTHOR}

Ignateva Anna Vladimirovna, Graduate Student of Department of Nature Management

National Research Tomsk State University

36, Lenin pr., Tomsk, Tomsk region, 634050, Russian Federation anna_tomsktsu@mail.ru

ORCID: 0000-0002-3620-7252 